\title{
ESCRITURA ACADÉMICA: VEHÍCULO DE REFLEXIÓN, CRISOL DE VOCES DOCENTES
}

\section{ACADEMIC WRITING: VEHICLE OF REFLEXION, CRUCIBLE OF TEACHING VOICES}

\author{
LAURA MACRINA GÓMEZ ESPINOZA * \\ ROXANA LILIAN ARREOLA RICO ** \\ CONCEPCIÓN HERNÁNDEZ ***
}

Rec.: 09-08-2020. Acept.: 01-12-2020. Publ.: 18-12-2020

DOI: http://doi.org/10.29035/ucmaule.59.79

\section{RESUMEN}

Se presentan resultados de una investigación realizada en la Universidad Pedagógica Nacional (México), con estudiantes de licenciatura y maestría que ejercen como profesores de educación básica en servicio (docentes-estudiantes). El estudio de corte cualitativo, en tanto se basa en un análisis interpretativo de la subjetividad expresada en narrativas, tiene el propósito de analizar sus reflexiones derivadas de la propia práctica docente, expresada en sus textos académicos, y desentrañar los procesos de escritura implicados. Los resultados Ilevan a evidenciar el valor que adquiere la escritura en la comunicación y comprensión del quehacer docente, abonando a procesos de identidad y transformación personal y profesional; también confirman la preocupación por una escritura correcta. Por otra parte, se advierte que textos de carácter reflexivo contribuyen a procesos de movilización de emociones y toma de conciencia de la labor profesional, que repercuten en transformar la mirada de sí y de la práctica docente.

Palabras clave: Escritura Académica, Práctica Docente, Formación de profesores.

\footnotetext{
* Universidad Pedagógica Nacional, Unidad Azcapotzalco, México. Imacrina@yahoo.com

** Universidad Pedagógica Nacional, Unidad Sur, México. roxarreola@yahoo.com.mx

*** Universidad Pedagógica Nacional, Unidad Sur, México.
} 


\section{ABSTRACT}

Results of an investigation carried out at the National Pedagogical University (Mexico) are presented, with undergraduate and master's degree students, who are teachers of basic education in service (teacher-students). The qualitative study has the purpose of analyzing their reflections, based on an interpretive perspective of narratives derived from their own teaching practice expressed in their academic texts, and unravelling the writing processes involved. The results lead to evidence the value that writing acquires in communication and understanding of the teaching task, contributing to processes of identity, and personal and professional transformation; they also confirm the concern for correct writing. On the other hand, it is noted that texts of a reflective nature contribute to processes of mobilization of emotions and awareness of professional work, which have an impact on transforming the view of oneself and of teaching practice.

Key words: Academic writing, teaching practice, teacher training.

\section{INTRODUCCIÓN}

La cultura escrita se entiende como las prácticas sociales mediadas por el lenguaje escrito (Hernández, 2008, 2016; Kalman, 2008) y constituye una red de significados compartidos que se construye con prácticas letradas, que incluyen leer, escribir, hablar, pensar y actuar alrededor de la escritura y los textos.

La escritura como manifestación del lenguaje es una actividad habitual en los entornos universitarios. Una gran parte del conocimiento que se elabora se expresa a través de textos que se leen y producen en una inextricable red de relaciones entre unos y otros, tanto en formatos monológicos como dialógicos. Escritura académica refiere a un constructo que se constituye en una aplicación y objeto de enseñanza en la universidad: los estudiantes están aprendiendo este tipo de escritura y al mismo tiempo deben practicarla (Camps \& Castelló, 2013; Cassany \& Morales, 2008).

Este tipo de escritura también remite a producciones orales y escritas que se realizan en el ámbito académico, tanto por los alumnos (trabajos, exposiciones, tesis, exámenes), como por los profesionales de la educación (manuales, ensayos, artículos, monografías). Es una práctica del lenguaje vinculada con las 
características del área de la disciplina profesional —en la cual se desarrolla-y con las formas de escritura propias de dicha área (Carlino, 2013). La escritura académica cumple diversas funciones, siendo la más evidente la comunicativa: al escribir transmitimos a alguien algún tipo de información.

Los humanos desarrollan actividad discursiva en diferentes ámbitos o esferas de comunicación, que dan lugar a formas de uso del lenguaje que se denominan géneros discursivos. En el ámbito académico se trata de tesis, informes, reseñas de libros, proyectos, apuntes, entre otros. Las situaciones y los géneros son construcciones sociales que poseen cierta estabilidad, pero al mismo tiempo son dinámicas y cambiantes (Camps \& Castelló, 2013).

De acuerdo con Camps y Castelló (2013) el sentido de las actividades y prácticas discursivas viene dado por la situación que las genera y por la forma en que los participantes las conciben. Así, algunos géneros se institucionalizan y adquieren una gran estabilidad, como el caso de los proyectos de intervención que exigen los programas de estudio de la Universidad Pedagógica Nacional (UPN), que propicia la participación de los individuos en las comunidades discursivas. Cualquier aproximación al estudio de dichas prácticas en la universidad debería situar el énfasis en la necesidad de que las actividades de lectura y escritura tengan sentido para los estudiantes.

Los proyectos de intervención en la UPN asumen una función formativa. En ella se implica la autorreflexión y el análisis de contextos que habrán de desatar una acción propositiva orientada a la mejora de la práctica y la identidad docente. En particular interesa la función comunicativa que asume la escritura para la expresión de formas de pensar y actuar, otorgando, desde lo institucional, un sentido y significado a la escritura como un instrumento para la transformación de prácticas.

De acuerdo con lo anterior resulta fundamental indagar sobre el sentido y significado que los docentes-estudiantes otorgan a la escritura, a partir de la experiencia y vivencia que tienen a lo largo del proceso formativo. Camps \& Castelló (2013) recuperan a Lea (2012), quien sugiere que el foco de atención se traslada a la construcción del sentido y de una identidad como autor, en este caso también en una identidad docente. Esto exige situarse en un nivel epistemológico en el que lo que cuenta es qué tipo de conocimiento se genera y para qué sirve o en qué esfera de actividad se sitúa. 
Los proyectos de intervención incluyen un apartado de análisis de la práctica docente y permiten articular los diversos sistemas de actividad (profesional, de enseñanza y aprendizaje, académica y social académica), propuestos por Camps \& Castelló (2013), lo cual representa una serie de tensiones y dificultades para el autor ya que debe producir un texto propio de la comunidad profesional y requiere aprehender las características básicas de este sistema de actividad que le exige cambios en sus acciones y en su identidad. Para Castelló, Iñesta \& Corcelles (2013) la resolución de estas tensiones pasa por repensar la forma en que se concibe el texto, su rol como escritor, las convenciones o recursos que son necesarios, las reglas de comunicación preestablecidas y su posición en la comunidad, aspectos que inciden de forma directa en el texto final que el estudiante produce.

Cuando se habla de producción de textos se entra al terreno de la alfabetización, entendida como un proceso centrado en el desarrollo continuo de destrezas discursivas escritas. Para designar la alfabetización que se lleva a cabo en los estudios de educación superior se ha acuñado la expresión "alfabetización académica" (Carlino, 2003, 2005; Nuñez, 2015), la cual implica el desarrollo de la competencia comunicativa desde la universidad.

Agregando a lo anterior, Carlino (2013) señala que la alfabetización académica se refiere al proceso de enseñanza para favorecer el acceso de los estudiantes a las diferentes culturas escritas de las disciplinas y conlleva dos objetivos: enseñar a participar en los campos propios del saber y enseñar prácticas de estudio adecuadas para aprender en él. En el caso de los docentes-estudiantes de la UPN en cuanto al segundo objetivo sobre la apropiación del conocimiento producido por ellos, se pretende que sean alfabetizados para que posean autonomía para la producción de textos escritos y la posibilidad de construir el sentido de un texto, con capacidad de decir lo que piensan y lo que interpretan, posicionándose frente a la realidad, asumiendo una forma de percibirla y de actuar en ella.

Construir un texto es un proceso complejo, que implica asumir una serie de etapas recursivas que ponen en juego factores que incluyen la naturaleza de la tarea, del contexto y del escritor; que incorpora elementos relevantes como la memoria de trabajo, la motivación o las emociones y los procesos cognitivos de interpretación y de reflexión (Álvarez \& Ramírez, 2006; Díaz, 2014). De ahí que sea importante indagar sobre el proceso de escritura de los docentes-estudiantes, ya 
que se asume que modifica no solo lo que intenta escribir sino incluso el posicionamiento respecto a la escritura y su práctica docente.

Montes \& López (2017) realizan una revisión muy completa en la que diferencian que literacidad y alfabetización académica se refieren a prácticas más generalizables, como las que se enseñan en asignaturas que suelen formar parte de los programas de estudio del nivel superior; en tanto literacidad y alfabetización disciplinar son prácticas altamente especializadas que ocurren en el marco de un dominio específico y restringido. Esta investigación se alinea con los primeros términos que exponen estos autores.

El concepto de alfabetización académica va de la mano del de literacidad académica. Según Carlino (2005; Cartolari \& Carlino, 2009; Carlino, 2017) se entiende como una práctica situada en contextos sociales e institucionales específicos (la educación superior y la investigación científica, sus comunidades y prácticas), por lo que no es algo que los alumnos deban poseer al ingresar a la universidad, sino que es tarea de la universidad socializarlos en dichas prácticas. Por lo tanto, la literacidad académica favorece el aprendizaje y la participación de los alumnos en las culturas escritas de las disciplinas, a través de una enseñanza que las preserve como tales.

\section{Problemática}

Uno de los aspectos poco atendidos en la investigación educativa en el nivel superior es aquel que tiene que ver con procesos lectores y de escritura, que sostienen la permanencia de los estudiantes en la universidad. Carlino (2005), señala que cuando dichos procesos no son favorables en relación con los propósitos educativos, suele pensarse que el problema es producto de los primeros años de la escolaridad. Se cree que la falta de comprensión lectora y de habilidades para escribir son cuestiones que se gestaron en el pasado, como consecuencia de una formación precaria, y que al nivel de educación superior sólo le queda centrarse en los problemas propios de la disciplina particular de la que se trate, sin considerar que la escritura y concretamente la alfabetización académica posibilitan la comprensión, abordaje y aprendizaje de las disciplinas. Frecuentemente, los académicos de la UPN renuncian a responsabilizarse de la tarea de proveer a los estudiantes de elementos fundamentales para pensar y aprender, bajo el supuesto de que los estudiantes arriban con esas herramientas. 
De acuerdo con Cardona, Castillo \& Calle (2009), esto afecta en la calidad académica de los programas educativos.

En esta investigación se analiza el caso de los docentes-estudiantes de la Licenciatura en Educación Preescolar y de la Maestría en Educación Básica de la Unidad UPN Sur de la Ciudad de México. Consideramos que la experiencia vivida en estos programas a lo largo de diez años, permitió observar que uno de los factores definitorios del desarrollo y de los resultados alcanzados, se relaciona con las dificultades que presentan para acceder a la comprensión y utilización de la teoría, así como para expresar de manera escrita las ideas propias y las de los autores revisados en sus clases.

Lo anterior se manifiesta en las aulas, donde predomina la entrega de trabajos académicos en los que abundan errores de ortografía y vicios en la redacción, además de un manejo inadecuado de ideas y escaso análisis crítico. Esta condición puede considerarse como factor importante en las dificultades que experimentan los docentes-estudiantes en su trayecto formativo.

Un concepto central es la formación, entendida como un proceso que no acaba nunca mientras el sujeto existe y que se enfoca en la construcción del ser, no fragmentado sino como totalidad, en la que se articulan múltiples dimensiones y posibilidades.

Según García (2006), al definir la formación como el conjunto de posibilidades de ser, nos acompaña en la travesía por el mundo, nos impulsa a pensar en el devenir, en las maneras como podemos trascender como sujetos sociales y nos diferencia de los seres puramente biológicos.

El enfoque que rige la investigación contempla la escritura como un proceso que va más allá de meras funciones utilitarias en la vida de las personas. Lo concebimos como un proceso que al desarrollarse nos construye como sujetos sociales, es un reflejo del contexto específico en que se produce, involucra procesos de formación que se han construido a largo plazo y evidencia aspectos sociales únicos en cada uno de los sujetos. Como resultado, la escritura construye subjetividad, forma sujetos capaces de asumir formas de acción y pensamiento propios en función de la situación en que se desenvuelvan. Así, el proceso de escritura se entiende como experiencia vital, cuyos límites están definidos por los 
sujetos y no totalmente en las exigencias externas dictadas por una racionalidad institucional.

Sin embargo, desde la perspectiva de esta investigación, lo que preocupa es el sujeto y el proceso por el cual se formó en esa dimensión: el lenguaje, la capacidad de enunciación, la aprehensión y creación del mundo por medio de él. Específicamente, la problemática que se aborda en esta investigación se refiere a los procesos de escritura y sus implicaciones en la formación docente, atendiendo a las siguientes preguntas:

¿Cuál es el papel que cumple la escritura en el proceso de conocimiento de las alumnas de la Licenciatura en Educación Preescolar y Maestría en Educación Básica, así como en la constitución y formación del sujeto?

¿Cuáles son las características de tipo personal, social e institucional que confluyen en el proceso de escritura?

¿Cómo perciben las docentes-estudiantes la problemática en torno al proceso de escritura académica en su proceso de formación?

\section{Objetivo}

La investigación se fundamenta en el estudio de la práctica docente de estudiantes a nivel de licenciatura y maestría, quienes de manera paralela se desempeñan como profesores de educación básica. El objetivo principal de la investigación es develar los procesos de escritura implicados en la práctica docente a partir de la reflexión en torno a la producción personal de las docentesestudiantes. Es decir, desentrañar los procesos de escritura implicados respecto al valor de ésta en el acto comunicativo y la interpretación del quehacer docente, la identidad docente, las emociones que se hacen presentes y cómo repercuten para transformar la mirada que las docentes-estudiantes tienen de sí mismas.

Los hallazgos de esta investigación aportan información para la mejora de las estrategias de enseñanza de los académicos de la UPN, a fin de impactar en la formación docente de los docentes-estudiantes, considerando las implicaciones manifestadas por las participantes en el ámbito personal, social, laboral y emocional. 


\section{Metodología}

En el aspecto metodológico, la investigación se fundamenta en propuestas de corte cualitativo, que dan importancia al aspecto subjetivo en la manera cómo se construye e interpreta la realidad social, la cual se recupera mediante la narrativa. Se busca la interpretación del significado de la acción social e individual a través del análisis del discurso, apelando a la importancia del lenguaje como constructor de realidad y como medio en el que se fusionan la dimensión subjetiva y objetiva.

Entre las perspectivas teóricas que buscan la comprensión del significado de los fenómenos sociales se encuentra la fenomenología, que es vista como una corriente que aporta la experiencia subjetiva de los hechos tal como se perciben. Por tanto, la investigación fenomenológica le asigna un papel principal a la experiencia subjetiva, ya que según Barbera e Inciarte (2012) constituye la fuente y base para alcanzar el conocimiento de la realidad social.

A partir de las ideas anteriores, se entiende por subjetividad el conjunto de procesos internos y externos que constituyen al sujeto en la dimensión de lo simbólico y que permiten una forma específica de inserción y desempeño al interior de una cultura.

La razón principal para el uso de la narrativa en la investigación educativa es que los seres humanos son contadores de historias. La narrativa es el estudio de la forma en que los seres humanos perciben el mundo. Existen diversas formas de ver la realidad educativa y una de ellas es desde la narrativa, mediante la escritura de relatos sobre la experiencia que permiten a los docentes en el contexto de la formación, descubrirse, reconocerse y transformarse (Chona, 2019).

La construcción narrativa ayuda a comprender aspectos del cómo se identifica el sujeto estudiante y docente sobre situaciones familiares significativas en su vida, sus percepciones acerca de la enseñanza y de aprendizaje, así como factores emocionales, dentro o fuera de la escuela, que identifican como relevantes en su proceso de constitución como sujetos sociales.

Se parte de la idea de que la narración es un aspecto intrínseco al ser humano, que expresa, por medio del lenguaje, nuestra historia y da cuenta de experiencias significativas a través de las que se llega a ser quien uno es. 
Esta investigación retoma el proceso de escritura a partir de reflexiones propias de nuestras docentes-estudiantes. Para ello se utilizaron como técnicas de recolección de información:

a) Narrativas sobre el "Análisis de la práctica docente propia", elaborados con base en las dimensiones propuestas por Fierro, Fortoul \& Rosas (2008).

b) Narrativas por escrito en donde relataron aspectos sobre el proceso de elaboración del escrito anterior, tales como: problemáticas y obstáculos enfrentados, percepción de transformación personal y de la práctica educativa, sentimientos y emociones provocados al realizar el texto y reconocimiento de la identidad profesional.

Para realizar el análisis se elaboró una matriz en donde se clasificaron las respuestas por indicadores y descriptores que dieron origen a las siguientes categorías analíticas:

- El significado de la escritura en el proceso de análisis de la propia práctica.

- La percepción de sí mismo respecto de los cambios que reconocen a partir de la elaboración de su texto.

- Las emociones y sentimientos que les provocó o experimentaron durante la producción de su escrito.

- Las problemáticas u obstáculos que las docentes-estudiantes enfrentan durante la escritura.

La selección de los participantes recuperó los casos que se consideraron más representativos y que conformaban los grupos escolares naturales, lo cual responde a un muestreo no probabilístico intencional en el que se contó con 21 docentes-estudiante del sexo femenino, lo cual es un rasgo característico de la población que se atiende, cuyas edades fluctúan entre 25 y 50 años, profesoras de educación básica en servicio (preescolar, primaria y secundaria). 


\section{Resultados}

El análisis incorpora voces de los docentes-estudiantes, con la aclaración de que únicamente han sido corregidos errores de tipeo y ortografía, para facilitar la comprensión de la lectura y respetar el sentido de la expresión de las participantes.

El significa do de la escritura en el proceso de a nálisis de la propia práctica.

El acto de escritura significó fundamentalmente un espacio de reflexión para el grupo de docentes-estudiantes. Algunas participantes admitieron debilidades preconcebidas para enfrentarse a la conducción de un grupo escolar. Entre las expresiones que dan cuenta de ello se encuentran las siguientes: "he venido replanteando mi inseguridad ante mis alumnos" (IMO4-MR), "mis clases eran aburridas y no estaban adecuadas para las necesidades de cada niño" (IM05), "soy más segura de mis acciones" (ICO6). También hubo a quienes el ejercicio les permitió entender hasta qué punto han tenido mejoría en sus propias estrategias educativas: "la percepción actual de mi misma ha cambiado, analizar mi proceso como docente me ayudó a detectar las cosas que debo mejorar" (IRO1).

Las participantes refieren que el acto de escribir permitió identificar momentos en los que sus debilidades se manifiestan y así generan estrategias para combatirlas e implementar nuevos planteamientos. Algunas de las expresiones son: "logré identificar aspectos que influyen en mi trato con los alumnos que vienen desde mi historia personal" (IRO2), "trato de ser más objetiva en el aula, dejar a los alumnos ser libres y experimenten a través de sus propios recursos" (IM06) y "me permitió valorar mi esfuerzo y dedicación" (IR03).

Se destaca que el hecho de escribir sobre su propia práctica les ha permitido entender cuáles han sido sus fallas, aciertos e incluso planificar nuevas estrategias en función de lo aprendido. Las docentes-estudiantes han reconocido: "puedo argumentar sobre mis planeaciones y contestar respuestas a los padres de familia con bases teóricas" (ICO6), "a partir de lo aprendido en la universidad y con el apoyo de la asistente que tenía comencé a cambiar mi forma de trabajo" (TMO1).

La escritura del texto también permitió reflexionar y tomar conciencia de diversos aspectos en los que deben mejorar. Por ejemplo, mencionan: "más bien me hace falta leer y prepararme" (IMO3), "me sirvió para reflexionar sobre aquello 
que debe ser modificado desde lo personal hasta lo profesional" (IR05), "es un escrito que me ha permitido recordar cosas que he realizado y permite que busque mejores estrategias" (IR07) y "me di cuenta de que era la ocasión de renovarme, salirme del ámbito de la certeza, de la llamada zona de confort, crecer, revalorizar mi propio desempeño, mirar de otra manera" (TRO4).

Las docentes-estudiantes señalan también aspectos relacionados con la responsabilidad social que implica su labor docente, lo cual se hace evidente en testimonios como: "Ios sentimientos que me provoca en mi análisis primero coraje de ver que hay personas que tienen los recursos para cambiar las cosasy no lo hacen" (IM07), "pero lo que más me dio pauta a trabajar fue el miedo, la frustración, de saber que teniendo un trabajo de impacto social, no aportará nada" (IM05) y, "sentí consuelo al darme cuenta que los culpables de la situación educativa no es totalmente de los maestros" (IRO2).

Se detectó que mediante la escritura del texto se hace un reconocimiento del impacto emocional de las malas prácticas que ellos realizan con sus alumnos, cuando dicen:

la problemática que adopté fue a raíz de poder observar las implicaciones negativas que había hacia los niños de parte de compañeras e incluso de las propias maestras, perjudicando la autoestima de los menores con comentarios, burlas, apodos, etc. Es por ello que decidí atender esta problemática y detener esta situación que a veces nadie pone interés en esto (ICO2).

A través de la escritura las docentes-estudiantes logran analizarse y revalorizarse personal y profesionalmente, cuando mencionan "analizarme fue un gran reto, auto evaluarme de una manera como yo me percibo sin tener prejuicios es algo difícil" (IM06), "senti tristeza al ver que por algún tiempo tenía una visión de lo que era ser docente (buena maestra) y cumplía con los estereotipos que los papás esperaban de mi" (IM06), "conforme he ido avanzando me da gusto saber en qué concepto me tienen mis alumnos y descubrir cómo cambio cuando estoy con ellos" (IM04).

Por último, un testimonio que refleja un impacto no sólo en el ámbito profesional sino incluso en el personal: "aunque meses atrás yo ya no le veía sentido a la vida, me di cuenta que soy un ejemplo tanto para mi hija como 
también para esos niños que dejan a nuestro cuidado y ellos aprenderán mucho de mí" (ICO4).

El análisis reveló que la elaboración del texto permitió al estudiante revalorarse personal y profesionalmente. Algunas expresiones elocuentes son: "a pesar de todas estas situaciones y del trayecto que tuve que seguir para llegar hasta donde estoy hoy en día, puedo decir felizmente: ¡AMO SER MAESTRA!" (TRO1), "sé que no soy la mejor maestra, pero siempre estoy dispuesta a aprender y prepararme para darles un mejor aprendizaje a mis niños, trato de planear mis situaciones didácticas según las actitudes de los niños, para un mejor trabajo en el aula" (TM03), y "Siento que me hace falta más experiencia para lograr mis expectativas, $y$, sobre todo creerme que soy una docente" (TCO5).

El hecho de poder reflexionar y autobservar sus acciones en el aula para plasmarlo por escrito, abre la oportunidad de construir y reconstruir su identidad. Les permite autoanalizarse y tomar conciencia de sus prácticas docentes. Posibilitó un cambio conceptual respecto de ser docente, se hace evidente en expresiones como: "considero que el ser docente es una acción social, humana y trascendental, porque en nuestra práctica existe un intercambio de conocimientos, ideas, valores y actitudes que se han construido socialmente $y$ culturalmente" (TRO3) y

propicia una gama de estados socio - afectivos y emocionales que podrían ser una herramienta para generar un cambio positivo en nuestra sociedad; sin embargo, desde mi perspectiva, existen factores ideológicos y políticos que merman la trascendencia humana de la docencia, pero que tampoco la inhiben por completo, porque podemos informarnos, concientizarnos y organizarnos para rescatar este enfoque (TRO3).

Asimismo, logran identificar condiciones que afectan su práctica docente como se expone en el siguiente testimonio:

las exigencias de la escuela privada donde laboraba, fueron más rígidas, no importaba el cómo, lo imprescindible era completar los libros, los de texto gratuitos además de los adquiridos por los padres de familia, comunicábamos los conocimientos sin tomar en cuenta a nuestros alumnos, sin conocer sus imperfecciones o sus habilidades, incapaces 
de aplicar lo aprendido en su contexto, ni a su realidad, lo importante eran las indicaciones de las autoridades que respondían a intereses mercantiles (TRO4).

Por otro lado, reconocen situaciones que deben considerar en sus prácticas y con ello modificar su manera de ser docente, por ejemplo, cuando mencionan:

los tiempos han cambiado, las alumnas y los alumnos presentan experiencias muy diversas; las conductas, actitudes y valores de igual forma, no son los mismos. Que no tendrían por qué ser iguales, ya que las estructuras globales (mundo) cambian de forma acelerada" (TRO4);

consideraba tener una mirada diferente que la de mis primeros años de docente. Ahora reflexiono, quizá menos soñadora, algo desilusionada, sí más consciente de la realidad educativa en México; pero siempre con la necesidad de vivir este mi vicio de la docencia como un ideal de transformación de la sociedad (TRO4).

En síntesis, la escritura toma un significado para las docentes-estudiantes en tanto les posibilita una serie de reflexiones y toma de conciencia en cuanto a la función social de su quehacer docente, fortalezas y debilidades, lo que las lleva a revalorarse como profesoras y personas. Simultáneamente, reconocen el compromiso y responsabilidad social que implica aspectos que se pueden mejorar y el impacto que pueden tener sus prácticas sobre los aprendices de educación básica, a fin de transformar su forma de comunicación y su práctica educativa.

La narrativa analítica de las estudiantes propicia autoanálisis y resignificación de su identidad docente, y pone al descubierto una serie de transformaciones en sus prácticas educativas, reconociendo contextos diversos en los que se desempeñan y el papel social activo que juegan como educadores. Un aspecto fundamental fue que las participantes identificaron dificultades de su propia práctica, lo que les permitió reflexionar en torno a su proceder cotidiano y encontrar la manera de superarlas. Reconocen el valor de procurar una mejoría constante en sus intervenciones educativas. 
La percepción de sí mismo respecto de los cambios que reconocen a partir de la elaboración de su texto

Se devela que la reflexión sobre la práctica docente las llevó a hacer una retrospectiva de su vida, un reconocimiento de su historia para comprender su presente. Evidencia de ello se muestra cuando se menciona: "desde que era niña soñaba con enseñar aunque no me veía como maestra, sin embargo en la escuela primaria apoyaba a mis compañeros cuando se les dificultaba algún tema" (TRO5), "el haber tomado la decisión de ser maestra es un sueño que surgió desde que era niña, convirtiéndose en una realidad cuando a los 18 años terminé la carrera técnica de asistente educativo" (TMO4), "nunca me imaginé que hasta mis 27 años me daría el tiempo para poder analizar qué fue lo que me impulsó para llegar a lo que soy ahora, y que mi gusto por la docencia remotamente venga desde mi niñez, cuando por las tardes después de hacer mis tareas de la escuela, lo único que me emocionaba era jugar a la maestra" (TRO1) y, "recuerdo los juegos de infancia, donde yo era la maestra, mis hermanas y primos mis alumnos" (TMO3).

Institucionalmente y de acuerdo con la intención de los programas educativos de la UPN, la escritura juega un papel relevante para la formación de los docentes, en tanto se asume que a través de ella se propicia la reflexión y esta constituye el primer paso para la transformación y mejora de la práctica docente. Este supuesto podemos constatarlo a partir del análisis realizado de las producciones escritas de las docentes-estudiantes que, a decir de ellas mismas:

una de las estrategias para una mejor labor educativa, es la constante reflexión que permite analizar y comprender situaciones referentes al proceso de docencia, se requiere ser profesional en la docencia, tener vocación y aplicar lo aprendido en las niñas y los niños (...) cambiando paradigmas en bien de la niñez (TCO1);

Hoy estoy segura que a pesar de llevar varios años trabajando con niños preescolares no he logrado vencer del todo algunas de mis inseguridades, miedos, limitaciones y obstáculos personales (TM04)

Con mi primera clase donde todos los sentimientos se encontraron y al finalizar mi jornada de trabajo me hice estas preguntas, ¿aquí es donde quiero estar? ¿a esto me quiero dedicar toda mi vida? mi respuesta fue sí, acompañada de una grande sonrisa en mi cara (TRO1). 
Se identificaron tres vertientes sobre las cuales las estudiantes se reconocen como agentes educativos que han experimentado transformaciones en: el ámbito conceptual del ser docente; la intervención educativa y revalorizar a sus alumnos dentro de los procesos de enseñanza y de aprendizaje.

La primera involucra un reconocimiento de problemas y cambios relativos a la práctica docente. Las participantes manifiestan que su práctica no es un proceso estático ya que existen factores que las obligan a mantenerse en constante actualización. El proceso de escritura permitió jerarquizar y hacer explícita la necesidad de realizar ajustes a planteamientos profesionales, es decir, identifican los albores de un cambio conceptual en ser docente: "he tenido que adaptarme a los cambios, los nuevos métodos, a las nuevas obligaciones, a las transformaciones sociales y al uso creciente de la tecnología ya que mucho tiempo fui una maestra tradicionalista" (TMO4); "por eso he tratado de explicar a lo largo de este escrito, el proceso que he llevado en mi práctica docente, misma que incluso considero ha evolucionado" (TRO4); "me sirvió para reflexionar sobre aquello que debe ser modificado desde lo personal hasta lo profesional" (IRO5).

La segunda se refiere a cambios en su intervención educativa, lo que corresponde a lo que buscan poner en práctica. De esta forma, admiten que los cambios en su quehacer educativo están profundamente relacionados con la interacción cotidiana, misma que han logrado analizar a partir del proceso de escritura desde la teoría: "mis estrategias son más didácticas de acuerdo a los aprendizajes esperados siguiendo mi rutina de trabajo diario, estoy en el proceso de ser más analítica y observadora" (TMO7); "los resultados me motivaron a seguir preparándome y a pensar en nuevas formas de abordar los temas" (TRO2); "mi desempeño con el paso de los años fue mejorando ya que todas las vivencias me han dejado saberes nuevos que se ven reflejados en mi práctica docente" (TCO1).

Por último, manifestaron los cambios en la intervención educativa que les permitieron reconocer un papel activo de sus alumnos. De esta forma, identifican la importancia de comprender la interacción docente-alumnos como una retroalimentación bilateral, continua, que permite mejorar la práctica: "he aprendido a observar a mis alumnos y notar alguna problemática para brindarles la atención que requiere, trabajando de manera inclusiva y aplicando estrategias adecuadas para que tengan un aprendizaje significativo" (TCO1); 
"logré percibir que el aprendizaje logrado por la mayoría de los integrantes del grupo era funcional puesto que no olvidaban fácilmente, lo transferían a otros contextos -como el familiar y social-y les permitía seguir aprendiendo" (TRO2).

En síntesis, lo que se puede observar es que la escritura de un texto académico de carácter reflexivo posibilita la resignificación del ser docente, así como el reconocimiento de diversas circunstancias que afectan o que deben considerar en su práctica como elementos de valoración del compromiso social que tiene su labor y de lo que significa la docencia, con los rasgos y características que ello implica y la apreciación o percepción que cada profesor tiene sobre sí mismo. Respecto de esto último, en los análisis realizados se observa con frecuencia la recuperación de su historia profesional, para arribar a la comprensión de por qué eligieron la docencia y cómo se han ido transformando.

Mirarse a sí mismos, posibilitó el reconocimiento de transformaciones, dando cuenta del desarrollo de nuevas habilidades e incluso creatividad. En este sentido, se ha identificado que el cambio en la práctica docente se encuentra estrechamente vinculado con la innovación; hay un reconocimiento del rol docente que va más allá de simplemente adaptar la práctica a determinadas exigencias del contexto educativo.

\section{Las emociones y sentimientos que les provocó o experimentaron durante la producción de su escrito.}

La escritura del texto permitió a los docentes-estudiantes hacer catarsis personal y percatarse de las emociones que han vivenciado en su práctica docente, ya que destacan respuestas asociadas con la sensación de frustración: "me siento frustrada ya que a veces tengo la idea pero no la puedo plasmar, no confío mucho en mi ya que tengo muchas inseguridades" (ICO4), "sentí enojo al notar que reproduzco situaciones, frustración al identificar la falta de apoyo institucional" (IRO2); "la elaboración del texto me contagio de muchos sentimientos y emociones, como alegría, enojo, frustración, confusión y miedo porque en él se retoman vivencias" (IRO3); y, "en algún momento me sentí frustrada al pensar que me equivoque de carrera al pensar que no cumplía con las expectativas de los padres de familia" (IM06). 
El proceso de escritura también generó estrés pues mencionan: "estrés emocional, ya que el tiempo que tengo para realizarlo es poco" (IMO1) y "estrés por la falta de tiempo para escribir" (IRO2).

Asimismo, escribir permitió a las docentes-estudiantes superar miedos que enfrentan al momento de la escritura: "en otro momento me sentí angustiada ya que al citar olvido poner año y página y luego no recuerdo de donde lo tomé" (IMO4).

Un elemento crucial fue el reconocimiento de sentimientos durante el desempeño de su labor docente: miedo, felicidad, enojo, frustraciones "la conformidad de mi parte al no querer avanzar más por el miedo a estar mal" (IM03-LG); "creo que me asustó mucho la clase de docente que era" (IM05).

Por otro lado, se identificaron testimonios que manifestaron sentir frustración vinculada con el proceso de escritura, por no saber cómo escribir: "al principio me sentí emocionalmente enojada porque no sabía cómo iniciar el texto y como tenía que ir relacionando las ideas" (ICO5), "cuando tengo que realizar escritos me siento impotente de no poder realizarlos al no tener las palabras correctas, no saber cómo empezar" (IM03); "sigo teniendo frustración para realizar un ensayo" (IM06) y "angustia por saber qué tenía y cómo tenía que iniciar pero después ya no sabía cómo ser más concreta o redactar lo que en realidad quería expresar" (IRO7).

La escritura también posibilitó sentir satisfacción al expresar "me ha ayudado a superar muchos miedos personales, entre los cuáles está el compartir y expresar mis ideas...también me ha fortalecido la elaboración del texto" (IR03); "saber que hay mucho por aprender todavía y que esto nos ayuda a ser mejores docentes me llena de satisfacción y de necesidad por conocer cada día más" (IRO1) y, "nostalgia, recuerdos y sobre todo satisfacción que a lo mejor cuando entré a trabajar no tenía experiencia pero sí gusto por lo que hacía" (ICO3).

No obstante, escribir generó motivación, como lo revela la siguiente expresión: "ya que cada que concluía la clase salía muy motivada para realizarlo" (IRO2); también se encontró que escribir provoca temores e inseguridad como lo expresan "esto me llevó a sentir inseguridad sobre mis tareas y miedo a los ensayos" (ICO6); "inseguridad de escribir lo que pienso" (IMO3). 
Indudablemente se pudo apreciar que la escritura del texto movilizó emociones en los autores, lo cual se hace evidente en testimonios como "escribir este texto me llena de nostalgia, emoción y satisfacción" (IRO1), "estoy muy segura que en el escrito externé mis enojos, molestias, tristezas, miedos y alegrías que vivo en mi práctica docente" (IR05), "causó nostalgia, también asombro al identificarme con otras maestras de mi historia" (IRO2), "me sentí muy bien puesto que amo mi trabajo y el compartir mi tiempo y experiencias con mis alumnos" (ICO1) y "la emoción que me despierta en mí, son las ganas de continuar actualizándome" (IR06).

Se puede decir que al escribir se desata una serie de sentimientos y emociones, tanto positivas (alegría, satisfacción, reconocimiento) como negativas (frustración, enojo, estrés, tristeza, miedo). La movilización de éstas a parece en dos sentidos:

1. Escribir permitió percatarse de las emociones implicadas en la realización de su práctica docente, mismas que se presentan en la interacción con los alumnos, sienten agobio por la multiplicidad de actividades y las limitaciones de tiempo. El hecho de que la población estudiantil sea mayoritariamente femenina implica que disponen de tiempo limitado para atender sus estudios, en tanto son madres, jefas de familia, trabajadoras y esposas.

2. Las emociones que se generan en torno al acto de escribir, asociado principalmente a las deficiencias que arrastran desde la formación básica, al respecto se percataron que el proceso de escritura provoca frustración y estrés, en tanto se sienten incapaces de realizar dicha tarea; se hacen evidentes las carencias de la formación previa.

\section{Las problemáticas u obstáculos que las docentes-estudiantes enfrentan durante la escritura}

El estudio llevó a configurar seis agrupaciones de expresiones al respecto. Un primer conjunto amplio refiere no tener un manejo adecuado del sistema de escritura; manifiestan desconocimiento de cómo plasmar ideas por escrito, expresar su experiencia, acomodar y enlazar ideas de forma que sean comprensibles. Algunas expresiones son las siguientes: "primero me topé con que no sé cómo redactar, tener claros los conectores entre las oraciones" (ICO3), 
"acomodar mis ideas" (IMO2), "el no saber redactar" (ICO6), "Ias principales problemáticas fue enlazar ideas... la idea central no se perdiera" (IR03), "no conocer las reglas ortográficas" (ICO5), problemas con el significado de palabras" (IM01) y, "usar las palabras correctas" (IMO3).

Otro conjunto de estudiantes alude a la intención comunicativa, ya que encuentran difícil hablar sobre lo que realizan en el aula, identificar lo que puede ser importante de comunicar como parte de su análisis y si en su escrito recuperan su práctica de forma objetiva y completa. Se encuentran expresiones como: "no sabía si mis anécdotas serían significativas para el lector" (IRO1), "no es sencillo, y más cuando se tiene una mente con prejuicios" (IM05), "y si estaba analizando o no mi práctica docente" (IR05). Asimismo, hay un reconocimiento de una funcionalidad de la escritura que es fundamental en este tipo de textos, que se expresa en la frase: "mi problema es no escribir para darme cuenta de lo que me está faltando por mejorar" (IR06).

Algunas de las docentes-estudiantes identifican falta de estrategias de escritura para organizar y expresar ideas, así como dificultad para argumentar bajo un sustento teórico. Unas de las expresiones son: "desconocer algunos temas en la docencia" (ICO1) y "no saber en dónde puedo apoyarme para realizar el escrito" (IM03). Una expresión más: "pareciera que mis escritos no tenían una base sólida y parecían incompletos, incluso poco entendibles" (ICO3).

Se evidencian creencias sobre la escritura, cuando las estudiantes conciben que un documento escolar sobre el análisis de su práctica docente debe ser extenso, de manera que enfrentan el obstáculo de que sus "ideas son muy cortas al momento de escribirlas" (IMO4) o que al escribir "soy muy concreta y no hago muchos énfasis en los textos" (IM06).

Algunas participantes refirieron obstáculos más de orden personal, tales como no contar con tiempo para elaborar escritos, puesto que tienen otras actividades escolares, además del trabajo como docentes e incluso los deberes familiares. Lo expresan de la siguiente manera: "la problemática relevante que he enfrentado es el tiempo para poderlo hacer" (IR07), "pero debido a la elaboración de las tareas de los otros módulos, el trabajo en la escuela y la familia me restaban horas para ello" (IRO2). 
En esta categoría las estudiantes señalan la importancia del acompañamiento por parte de los docentes de la UPN, ya que consideran que contribuye a enfrentar el reto de escribir: "cuando nos presentó el maestro un ejemplo observé que era parecido y me impulsó a integrar más información, sin embargo en este momento estoy con la inquietud de revisarlo para ver que más le puedo agregar" (IR07), "el apoyo que nos brindan los profesores sobre la información proporcionada y las aclaraciones que nos dan sobre alguna duda" (IMO1), "yo pensé que en la universidad los profesores me iban a guiar o a explicar paso por paso en las actividades de ensayos o escritos" (ICO6) y ella misma concluye "pero no, entendí que es sólo leer varias veces mis propios escritos para poder realizarlos" (IM05), "no saber en dónde puedo apoyarme para realizar el escrito" (IM03). Hay quienes expresan como obstáculo no saber "realizar las citas" (IM07) y "citar en estilo APA" (IMO6).

Finalmente, un docente mencionó la utilidad que reporta poder contar con material de apoyo para emprender la tarea de la escritura, al expresar "sin embargo me agrada la idea de contar con material de apoyo, para tener un mejor conocimiento" (IMO1).

Los obstáculos que enfrentan las estudiantes en la elaboración de textos refieren a la literacidad académica, puesto que reconocen que este tipo de textos tiene especificidades en su construcción. Por lo tanto, requieren contar con apoyos para su elaboración, una guía de cómo realizarlos. Esto indica que admiten que se requiere aprender a elaborarlos, lo que remite a la necesidad de contar con un acompañamiento en el proceso de escritura.

Se configura que en la producción de un texto con características reflexivas sobre la propia práctica docente sigue prevaleciendo la idea de que escribir es un proceso que se sustenta en el conocimiento del sistema de escritura que implica saber ortografía y gramática, tener suficiente vocabulario y sintaxis para construir enunciados correctamente. Inclusive, predomina la creencia de que la cantidad de hojas escritas es una manera de mostrar destreza en la elaboración de un trabajo escolar de esta naturaleza.

Los datos revelan que existe el reconocimiento de que la escritura académica requiere, primero, un soporte conceptual de lo que se está expresando por escrito, desde el ámbito disciplinar en el que se encuentran las estudiantes desarrollando estudios universitarios. Segundo, un acompañamiento que permita diferenciar lo 
que es pertinente incluir en las producciones escritas, la manera de construir escritos acordes con lo esperado, e inclusive que la institución habría de ser partícipe de este proceso como parte de sus funciones educativas.

Esto se reconoce como alfabetización académica que la UPN debiera incorporar en sus programas curriculares. La escritura implica dedicación de tiempo que la mayoría de las docentes-estudiantes tiene limitado, debido al perfil de esta población; en su mayoría mujeres, que trabajan en el sistema educativo jornadas completas y/o ampliadas, atienden los menesteres de su familia, son sostén principal del hogar y asisten por las tardes a tomar sus cursos de licenciatura o maestría.

\section{CONCLUSIONES}

Esta investigación destaca la importancia del acto de escritura como un hecho comunicativo y reflexivo para mejorar la práctica docente. Asimismo, se evidencia que, dentro de los procesos de formación de profesores, en la escritura académica están presentes tensiones y coyunturas que tienen un impacto emocional.

Se constata que las condiciones específicas de las docentes-estudiantes restringen los avances en materia de escritura debido no solo a sus limitaciones de tiempo, ya que son estudiantes y trabajadoras, sino principalmente por las carencias que tienen sobre el sistema de escritura.

Se observa que prevalece una creencia generalizada de que la escritura es algo simple, que basta con practicar de manera continua para perfeccionarla. No obstante, una vez que se pide a las docentes-estudiantes reflexionar sobre su práctica educativa a partir de escritos generados por ellas mismas, toman conciencia de las dificultades que enfrentan en su labor cotidiana. Esto indica que sus textos no fueron meramente descriptivos, sino que les permitieron establecer análisis sobre distintos momentos de su labor docente.

Las participantes concientizaron que las prácticas de escritura continua es un elemento fundamental para registrar acciones de su quehacer docente y sirve para reflexionar; reconocieron que la interacción con sus alumnos es fundamental para generar otras perspectivas de retroalimentación y planificar nuevas estrategias. Así, la investigación revela que las docentes-estudiantes logran trascender lo descriptivo en favor de lo analítico-reflexivo. 
Las docentes-estudiantes reconocieron que escribir es un proceso complejo, que implica una gran dificultad para elaborar documentos $y$, en consecuencia, obtener el título de licenciatura o el grado de maestría. En este sentido, se identificó que esta situación debe atenderse en la educación superior y, por tanto, queda pendiente el cumplimiento de la obligación institucional de otorgar acompañamiento a los universitarios en la producción de textos escritos que el propio programa educativo les exige.

Así, la alfabetización académica durante el proceso de escritura y la producción escrita de nuestros estudiantes resulta fundamental para fortalecer dicho proceso, moldear y modelar las habilidades, así como proporcionar material o recursos. Por tanto, no es posible negar la responsabilidad institucional que los docentes universitarios tienen sobre la formación de los profesores de educación básica.

De acuerdo a lo encontrado, no olvidar que escribir es un reto emocional e intelectual, así como una oportunidad de crecimiento personal y profesional.

\section{REFERENCIAS BIBLIOGRÁFICAS}

Álvarez, T., \& Ramírez, R. (2006). Teorías o modelos de producción de textos en la enseñanza y el aprendizaje de la escritura. Didáctica, 18, 29-60. DOI: https://dx.doi.org/10.5209/DIDA

Barbera, N., \& Inciarte, A. (2012). Fenomenología y hermenéutica: dos perspectivas para estudiar las ciencias sociales y humanas. Multiciencias, 12(2), 199-205. Recuperado de https://www.redalyc.org/pdf/904/90424216010.pdf

Cardona, E., Castillo, S., \& Calle, B. (2009). Una práctica de lectura académica en una experiencia de formación de docentes universitarios. Revista Internacional de Investigación en Educación, 7(2), 371-382. Recuperado de https://www.redalyc.org/pdf/2810/281021548012.pdf

Camps, A., y Castelló, M. (2013). La escritura académica en la universidad. REDU Revista de Docencia Universitaria, 17(1), 17-36. DOI: https://doi.org/10.4995/redu.2013.5590 
Carlino, P. (2003). Alfabetización académica: Un cambio necesario, algunas alternativas posibles. Educere, 6(20), 409-420. Recuperado de https://www.redalyc.org/pdf/356/35662008.pdf

Carlino, P. (2005). Escribir, leer y aprender en la universidad: una introducción a la alfabetización académica. Fondo de Cultura Económica.

Carlino, P. (2013). Alfabetización académica diez años después. Revista Mexicana de Investigación Educativa, 18(57), 355-381. Recuperado de https://www.redalyc.org/pdf/140/14025774003.pdf

Carlino, P. (2017). Leer y escribir en las ciencias sociales en universidades argentinas Enunciación, 22(1), 110-124. DOI: https://doi.org/10.14483/22486798.12350

Cartolari, M., \& Carlino, P. (2009). Formación docente, concepciones y prácticas de lectura y escritura: una revisión bibliográfica. I Congreso Internacional de Investigación y Práctica Profesional en Psicología XVI Jornadas de Investigación Quinto Encuentro de Investigadores en Psicología del MERCOSUR. Universidad de Buenos Aires.

Cassany, D., \& Morales, O. (2008). Leer y escribir en la universidad: Hacia la lectura y la escritura crítica de géneros científicos. Revista Memoralia, 5(2), 69-82.

Castelló, M., Iñesta, A. \& Corcelles, M. (2013). Ph. D. students' transitions between academic and scientific writing identity: learning to write a research article. Research in the Teaching of English, 47, 442-478. DOI: https://doi.org/10.6018/rie.35.2.246011

Chona, J. (2019). Experiencia, narrativa y formación. Apuntes para la investigación e intervención educativa. En A. Jiménez (Coord.), Aulas para la imaginación. La formación desde la animación sociocultural de la lengua (pp. 51-73). México: UPN.

Díaz, A. (2014). Retórica de la escritura académica. Pensamiento crítico y argumentación discursiva. Editorial Universidad de Antioquia. 
Fierro, C., Fortoul, B. \& Rosas, L. (2008). Transformando la práctica docente. Una propuesta basada en la investigación-acción. Paidós.

García, C. \& Correa, A. (2012). Formación y gusto por la escritura y la lectura a luz de las ideas de Friedrich Nietzsche como ámbito de estudio de la Educación Corporal. Curitiba, 44, 255-273. Recuperado de https://www.scielo.br/pdf/er/n44/n44a16.pdf

Hernández, G. (2016). Literacidad académica. UAM.

Kalman, J. (2008). Discusiones conceptuales en el campo de la cultura escrita. Revista Iberoamericana de Educación, 46, 107-134. Recuperado de https://rieoei.org/historico/documentos/rie46a06.pdf

Lea, M. R. (2012). New Genres in the Academy: Issues of Practice, Meaning Making and Identity. In M. Castelló, C. Donahue (ed.). University Writing: Selves and Texts in Academic Societies (Studies in Writing, Volume 24), Emerald Group Publishing Limited, 93-109.

Montes, S., \& López, G. (2017). Literacidad y alfabetización disciplinar: enfoques teóricos y propuestas pedagógicas. Perfiles Educativos 39(155), 162-178. Recuperado de http://www.scielo.org.mx/scielo.php?script=sci_arttext\&pid=S0185$26982017000100162 \&$ lng $=e s \& \mathrm{nrm}=$ iso

Nuñez, J. (Coord.) (2015). Escritura académica. De la teoría a la práctica. Pirámide.

Reguera, A. (2014). La escritura académica en la universidad: literacidad, géneros discursivos e interacción dialógica. Revista Digital de Políticas Lingüísticas, 6(6), 69- 77. Recuperado de https://revistas.unc.edu.ar/index.php/RDPL/article/view/8730 